\title{
INTERDISCIPLINARIDADE, SEGURANÇA E QUALIDADE NO ATENDIMENTO AO PACIENTE SUBMETIDO À
}

GASTROPLASTIA

\section{INTRODUÇÃO}

Um dos reflexos do crescimento da obesidade no Brasil é a busca - cada vez maior - por tratamentos para redução de peso. Neste cenário, o número de cirurgias bariátricas realizadas entre os anos de 2012 e 2017 aumentou 46,7\% . Tal cenário repetese também nesta instituição com aumento de $34,48 \%$ entre os anos de 2017 e 2018. Dada a situação, é necessária uma abordagem interdisciplinar para que o acompanhamento deste paciente seja completo, seguro e apto a superar as expectativas dos clientes. A nova abordagem vem sendo realizada desde agosto de 2018 e já apresentou resultados.

\section{OBJETIVO}

Reduzir, com segurança, o tempo de internação dos pacientes submetidos à cirurgia bariátrica mediante início precoce do acompanhamento fisioterapêutico.

\section{METODOLOGIA}

Após comunicação da equipe de enfermagem sobre o nível de consciência do paciente, o primeiro atendimento é realizado no RPA através do uso ativo de incentivador respiratório, focando na manutenção do bom volume pulmonar. Em seguida, o paciente é encaminhado ao leito de internação e, após acomodação do mesmo, é iniciada a segunda fase do acompanhamento, cujo foco consiste em retirar o paciente do leito e iniciar a deambulação precoce ${ }^{2}$. Nesta fase, é utilizado aplicativo de celular que identifica a quantidade de passos dados e a distância percorrida pelo doente sendo possível que $o$ mesmo acompanhe seu desempenho e tenha estimulo para superá-lo. Esta ação também prepara o paciente para os desafios encontrados após a alta hospitalar e as duvidas são esclarecidas durante todo o processo até a alta hospitalar.

\section{RESULTADOS}

No período de agosto a outubro de 2018, 18 pacientes foram submetidos ao procedimento cirúrgico nesta instituição e todos tiveram alta hospitalar no prazo máximo de 36 horas, conforme estipulado no protocolo estabelecido. Não houve reinternação de nenhum paciente que pudesse ter relação com o procedimento cirúrgico realizado.

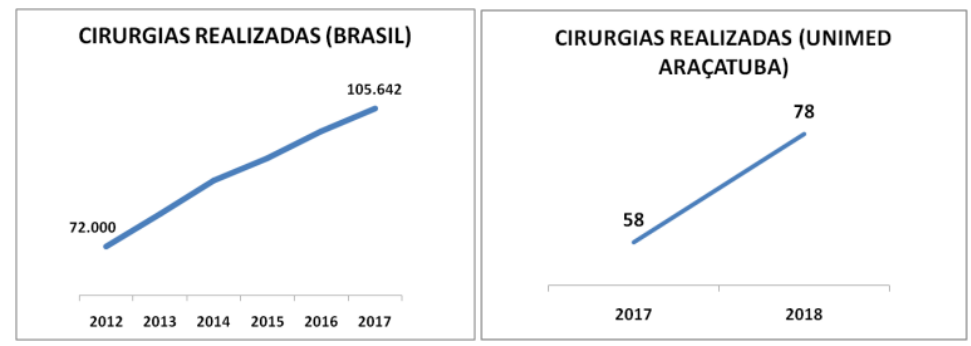

MÉDIA DE PERMANENCIA (em horas)

55

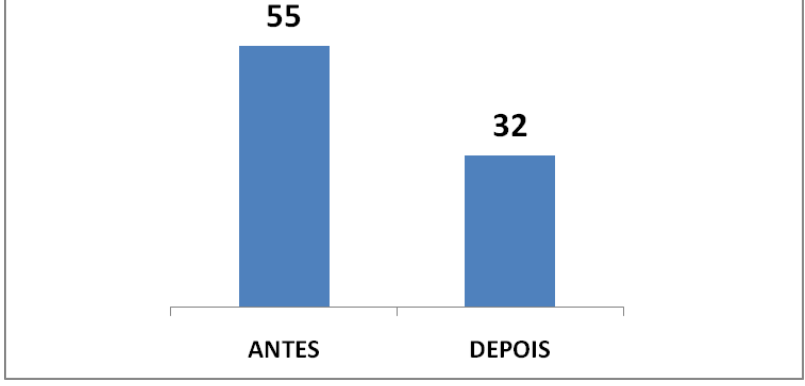

\section{CONCLUSÃO}

Esta abordagem interdisciplinar (médicos, enfermagem e fisioterapia) contribuiu para que os pacientes deste projeto obtivessem alta precoce com segurança mediante início antecipado da saída do leito e deambulação, evitando que estes pacientes fossem expostos a riscos infecciosos e de tromboembolismo venoso de maneira desnecessária.

\section{REFERÊNCIAS}

1 - https://www.sbcbm.org.br/numero-de-cirurgias-bariatricas-no-brasil-aumenta-467/

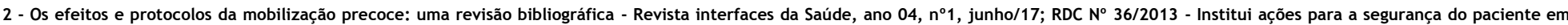
serviços de saúde;Palavra chave: Gastroplastia, Mobilização Precoce, Segurança do Paciente; Anvisa - Gestão de Riscos e Investigação de Eventos Adversos.

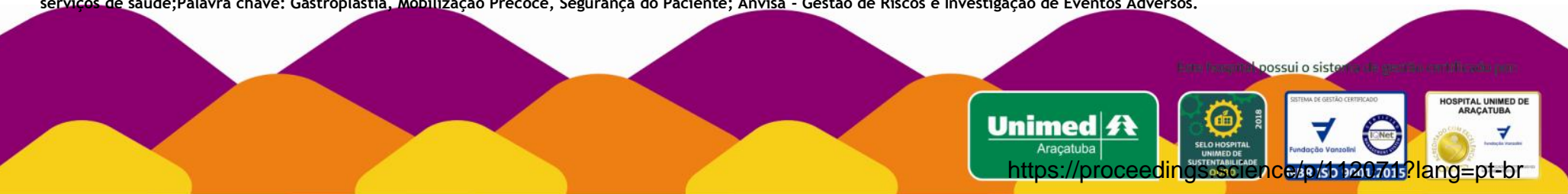

